Distribution of this document is unlimited.

\begin{abstract}
MODIFICATION OF VESTIBULAR RESPONSES AS A FUNCTION
OF RATE OF ROTATION ABOUT AN EARTH-HORIZONTAL AXIS*
\end{abstract}

Manning J. Correia and Fred E. Guedry, Jr.

Bureau of Medicine and Surgery

MRO05.13-6001.1.129

NASA Order R-93

Approved by

Captain Ashton Graybiel, MC, USN

Director of Research
Released by

Captain H. C. Hunley, MC, USN Commanding Officer

* This research was conducted under the sponsorship of the Office of Advanced Research and Technology, National Aeronautics and Space Administration.

U. S. NAVAL AEROSPACE MEDICAL INSTITUTE

U. S. NÄVAL AVIATION MEDICAL CENTER PENSACOLA, FLORIDA 


\section{SUMMARY PAGE}

\section{THE PROBLEM}

To compore nystogmic and subjective responses elicited at $10 \mathrm{RPM}$ with responses elicited at 30 RPM when the axis of rotation was horizontal.

\section{FINDINGS}

When the same subjects were rotated about an Earth-horizontal axis at 10 and 30 RPM, the following differences in responses were noted: 1) Subjects who produced a unidirectional horizontal nystagmus throughout rotation at 10 RPM produced a reversing horizontal nystagmus affer an interval (30-60 seconds) of rotation at 30 RPM. 2) Subjects, who gave veridical estimates of body orientation at 10 RPM, became disoriented at 30 RPM when nystagmus commenced reversing. At both 10 and 30 RPM a cyclic modulation of nystagmus was related to orientation relative to gravity.

As in previous studies, sickness was produced by rotation about a horizontal axis, and a relationship between mental task and incidence of sickness was again noted.

\section{ACKNOWLEDGMENTS}

The authors wish to express appreciation for the efforts of L. J. Roberts, A. Thomas, G. T. Turnipseed, and J. W. Norman for their assistance in this experiment. 


\section{INTRODUCTION}

It has recently been demonstrated (1-3) that rotation of a subject about an Earth horizontal axis produces responses which differ in several respects from those obtained for equivalent rotation about an Earth-vertical axis. Responses during horizontal-oxis rotation may be summarized as follows: During constant velocity rotation, for periods up to five minutes at certain velocities, rotation is perceived continuously, and unidirectional horizontal nystagmus persists throughout the rotation period. Following deceleration from constant velocity rotation, the expected experience of postural counterrotation is either absent or greatly reduced, and postrotational horizontal nystagmus is significantly attenuated.

During constant velocity rotation, when the axis of rotation and the longitudinal body axis are horizontal, a subject is continuously reoriented relative to gravity. During comparable rotation with the axes vertical, the subject maintains a constant orientation relative to gravity. Hence, although equivalent angular acceleration can be imparted to the horizontal semicircular canals in attaining constant velocity in these two situations, only horizontal-axis rotation involves continuous reorientation of the vestibular structures relative to gravity.

The receptors relevant to the effects associated with horizontal-axis rotation hove been the subject of some speculation. Benson and Bodin (1) hove suggested semicircular canal involvement and explain the unique responses during horizontal-axis rotation by a triveling deformation of the membranous canals due to the action of gravity on liie endolymph-filled membranous ducts which have slightly different specific gravity than the surrounding perilymph. Guedry $(3,4)$, on the other hand, has suggested that nystagmus may be produced when the otolith structures are stimulated by a change in linear acceleration, in this case by a change in orientation relative to gravity.

\section{PROCEDURE}

\section{SUBJECTS}

Twenty men, officer and cadet flight candidates in the Naval Aviation Training Program, participated in this experiment. These subjects had passed recent flight physical examinations and had no apparent symptoms of vestibular disorder. Of these twenty subjects, only eight were able to complete the experimental sequence. The remainder either requested to withdraw or were stopped due to sickness.

\section{APPARATUS}

The apparatus used was the Human Disorientation Device (HDD) and its bioinstrumentation (5). With in the HDD is a chair which was prepositioned so that the longitudinal body axis was aligned with the axis of rotation which, in turn, was 
horizontal. The chair is enclosed by a spherical, light-tight capsule. During rotation each subject was fastened to the rotating device by a head and body harness to minimize head or body motions relative to the rotating frame. Corneoretinal potentials were amplified and filtered by a system with an upper cutoff of $25 \mathrm{cps}$ and at a time constant of 1.5 seconds. A sinusoid potentiometer was used to record instantaneous orientation of the subject relative to gravity, and a switch permitted subjects to signal estimates of body position. Signals were passed through sliprings to an eightchannel Sanborn recorder.

\section{METHOD}

Each of the eight subjects who completed this experiment was exposed to four rotation trials, two trials at $10 \mathrm{RPM}$ and two trials at $30 \mathrm{RPM}$. For each velocity, one rotation trial was in a clockwise direction, CW (to the subject's right), and one rotation trial was counterclockwise, CCW (to the subject's left). Order of presentation of velocity magnitude and direction of rotation was counterbalanced over subjects. In each trial the subject was accelerated at $20 \% / \mathrm{sec}^{2}$ to either 10 or $30 \mathrm{RPM}$, maintained at that velocity for 120 seconds, then decelerated at $20 \% / \mathrm{sec}^{2}$ to a stop.

Horizontal and vertical components of eye movements were recorded during the entire rotation period. Also, prior to the test runs on four of the subjects, eye movements were recorded while the subject was slowly rotated through 360 degrees as a check for positional and spontaneous nystagmus. Of the eight subjects who completed the experiment, four were asked to signal by pressing a key when they passed through the nose-up and the nose-down positions; the other four subjects were required to perform mental arithmetic during rotation. Following completion of each trial, subjects were asked to describe body motions they had experienced during rotation. All runs were performed in darkness with each subject instructed to keep his eyes open and to stare "dead ahead."

\section{RESULTS}

\section{NYSTAGMUS}

\section{Time Course of Response}

Presented in Figure 1 are recordings of horizontal nystagmus obtained from the same subject during comparable time intervals following the onset of angular acceleration for CW horizontal-axis rotational velocities of 10 and 30 RPM. It may be observed that throughout rotation at 10 RPM, nystagmus was unidirectional, the direction being that of the response initiated by the angular acceleration. For 30 RPM, nystagmus became bidirectional, i.e., reversing in direction, during constant angular velocity.

To compare the average time course of the nystagmus in terms of magnitude and direction for 10 and 30 RPM, the velocity of the slow phase of each nystagmic 


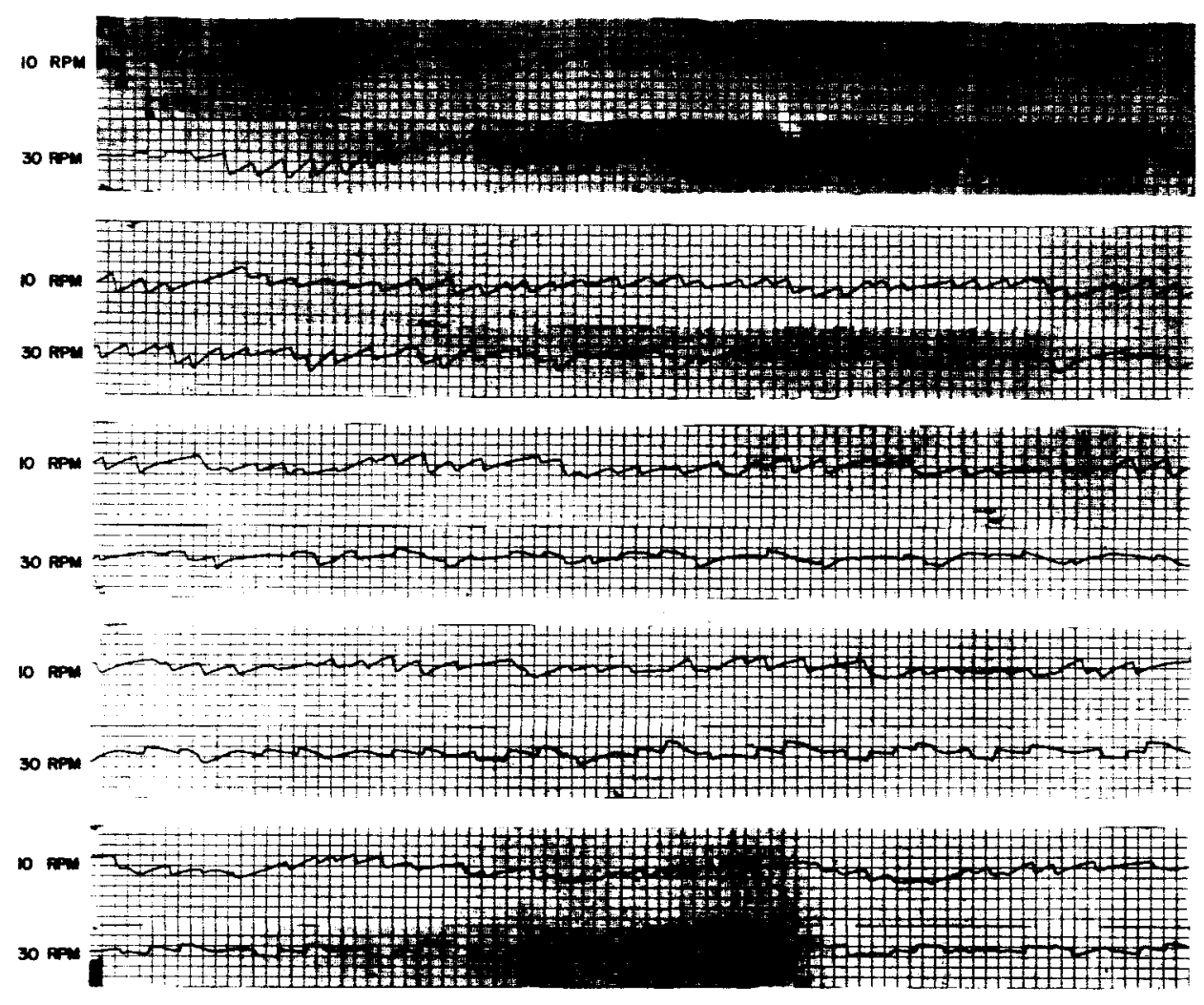

Figure 1

Recordings of horizontal nystagmus produced by the same subject during comparable intervals of clockwise horizontal-axis rotation at velocities of 10 and 30 RPM.

beat for each subject was measured for 120 seconds following the onset of angular acceleration. During some one-second intervals, since nystagmus reversed, the slow phase of the nystagmus was in different directions; hence, the mean slow phase velocities for each direction were obtained separately. Mean plots for the 10 and 30 RPM CW rotations are presented at the top of Figure 2; mean plots for the 10 and 30 RPM CCW rotations are at the bottom of Figure 2. Each point in Figure 2 is bosed on eight subjects. 


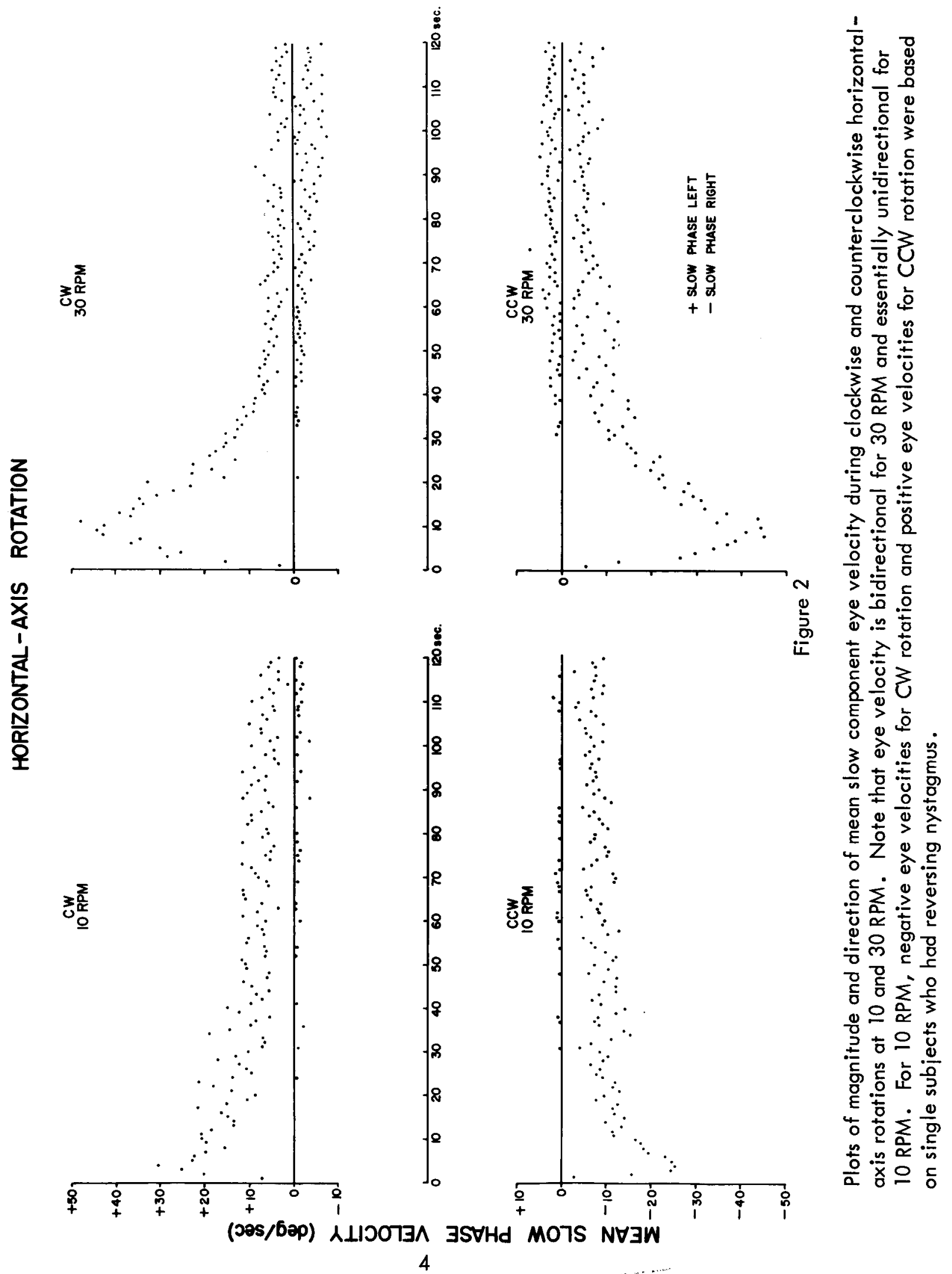


From Figure 2, it is obvious that 10 RPM and 30 RPM produced different responses:

During angular acceleration to 10 RPM and a short time thereafter, the nystagmus magnitude* and direction corresponded approximately to the classical response observed during and following angular acceleration about an Earth-vertical axis. However, nystagmus did not return to zero baseline but remained unidirectional throughout rotation with its magnitude oscillating cyclicly but never reaching the zero baseline.

Exceptions were noted for two of the eight subjects. These two subjects produced a reversing nystagmus during constant angular velocity for one direction of rotation at 10 RPM. Examination of eye movement recordings obtained under static conditions revealed that both of these subjects had a spontaneous nystagmus. When rotation was of a direction to augment the spontaneous nystagmus, the response remained unidirectional throughout the rotation period. When rotation was of opposite direction, the subjects produced a reversing nystagmus after twenty to thirty seconds of constant angular velocity. The points across the baseline from the preponderance of points plotted in the 10 RPM trials of Figure 2 were contributed almost exclusively by these two subjects.

For 30 RPM the response to angular acceleration was similar to that produced at 10 RPM but it was greater in magnitude due to the greater "acceleration $x$ time" product. However, whereas the 10 RPM response generally did not return to zero baseline, the 30 RPM response returned to zero baseline within fifty seconds from onset of angular acceleration. Seven of the eight subjects produced a definite reversing nystagmus within sixty seconds of 30 RPM. One subject produced a unidirectional response throughout both the 10 and 30 RPM trials. The nature of the reversing nystagmus was such that the magnitude oscillated sinusoidally and decayed until the nystagmus was of about equal magnitude in either direction about zero velocity at eighty seconds. Since nystagmus was averaged by one-second time intervals rather than at particular points in the rotation cycle, the modulation of nystagmus is somewhat obscured by the graphic presentation of Figure 2, but the time course of nystagmus independent of cyclic modulation is apparent.

Relationship of Direction and Magnitude of Nystagmus to Body Orientation

The relationship of direction and magnitude of slow-phase velocity of nystagmus to body position relative to gravity was examined by comparing the nystagmus response - - - - - - - -

* Nystagmus attains cyclic peaks which exceed the magnitude of nystagmus produced by vertical-axis stimulation. This was established by comparing responses produced by identical anguiar accelerations in vertical-and horizontal-axis stimulus configurations. Eight men not included in the nain experiment served as subjects; angular acceleration was $20^{\circ} / \mathrm{sec}^{2}$ to a rotational velocity of $10 \mathrm{RPM}$. 
to the sinusoid potentiometer recording as shown in Figure 3 . The potentiometer recording, while describing body orientation, may also be interpreted as a representation of the component of the gravitational linear acceleration vector acting along the horizontal head axes at any given time. For example, as illustrated in Figure 4, when the subject was in a nose-up position $(0)$ or nose-down position $\left(180^{\circ}\right)$, the gravity component would be maximum along the front-back head axis $(+x,-x$ axis) and minimum along the left-right $(+y,-y$ axis). When the subject was in nose-right or noseleft position, the component would be maximum along the $y$ head axis and minimum along the $x$ head axis. The directions of the linear acceleration vector relative to the head axes are summarized in Figure 4, and it should be noted that when rotation is $\mathrm{CW}$, the $90^{\circ}$ position is equivalent to the $270^{\circ}$ position when rotation is $\mathrm{CCW}$. During $C W$ rotation, $90^{\circ}$ position is attained after 90 degrees of angular displacement, whereas during $\mathrm{CCW}$ rotation, an angular displacement of 270 degrees from $0^{\circ}$ position is required to reach the $90^{\circ}$ position.

The cyclic relationship between magnitude and direction of nystagmus and direction of linear acceleration (gravity) is illustrated in the polar plots of mean nystagmus magnitude presented in Figure 5. The reversing nystagmus generated during 30 RPM was modulated so that fast phase right (nystagmus right) occurred when the linear acceleration $(q)$ was directed to the subject's right; nystagmus left was keyed to linear acceleration (g) directed left; zero eye velocity occurred just after the 00 and $180^{\circ}$ positions. Even for the sustained unidirectional nystagmus, generated during 10 RPM, magnitude was cyclicly modulated in that maximum slow phase velocity occurred between displacements of 180 degrees - 270 degrees and minimum slow phase velocity occurred between displacements of 0 degrees -90 degrees. This was true for either rotation direction (CW or CCW) if the displacements are defined as in Figure 4.

Each point in Figure 5 is the mean instantaneous slow phase eye velocity for seven subjects* averaged over two cycles of rotation and plotted at 30-degree intervals.

The exact points of maximum and minimum response for both 10 and 30 RPM varied among subjects, within a range of 40 degrees, but generally for 30 RPM,maximum nystagmus left lagged maximum linear acceleration left, maximum nystagmus right lagged maximum linear acceleration right, and zero eye velocity lagged zero acceleration along the left-right axis $\left(0^{\circ}\right.$ and $\left.180^{\circ}\right)$. For $10 \mathrm{RPM}$, maximum eye velocity occurred when the linear acceleration was directed so as to augment the ongoing response, and minimum eye velocity occurred when the linear acceleration was directed so as to inhibit the response.

- - - - - - - -

*At 10 RPM, the reversing nystagmus responses from subjects with spontaneous nystagmus were not included, and at 30 RPM, the subject with continuous nystagmus was not included. 

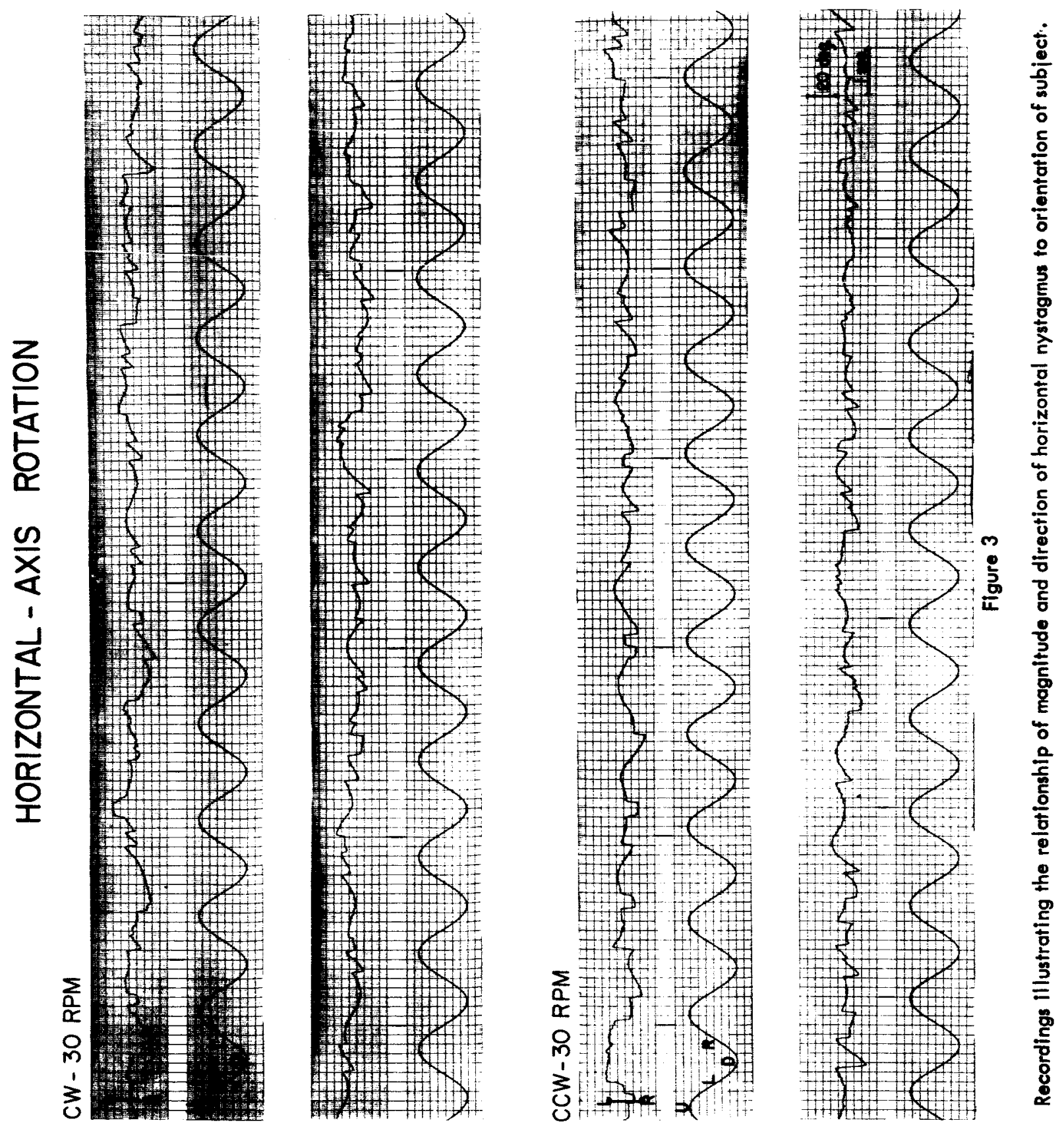


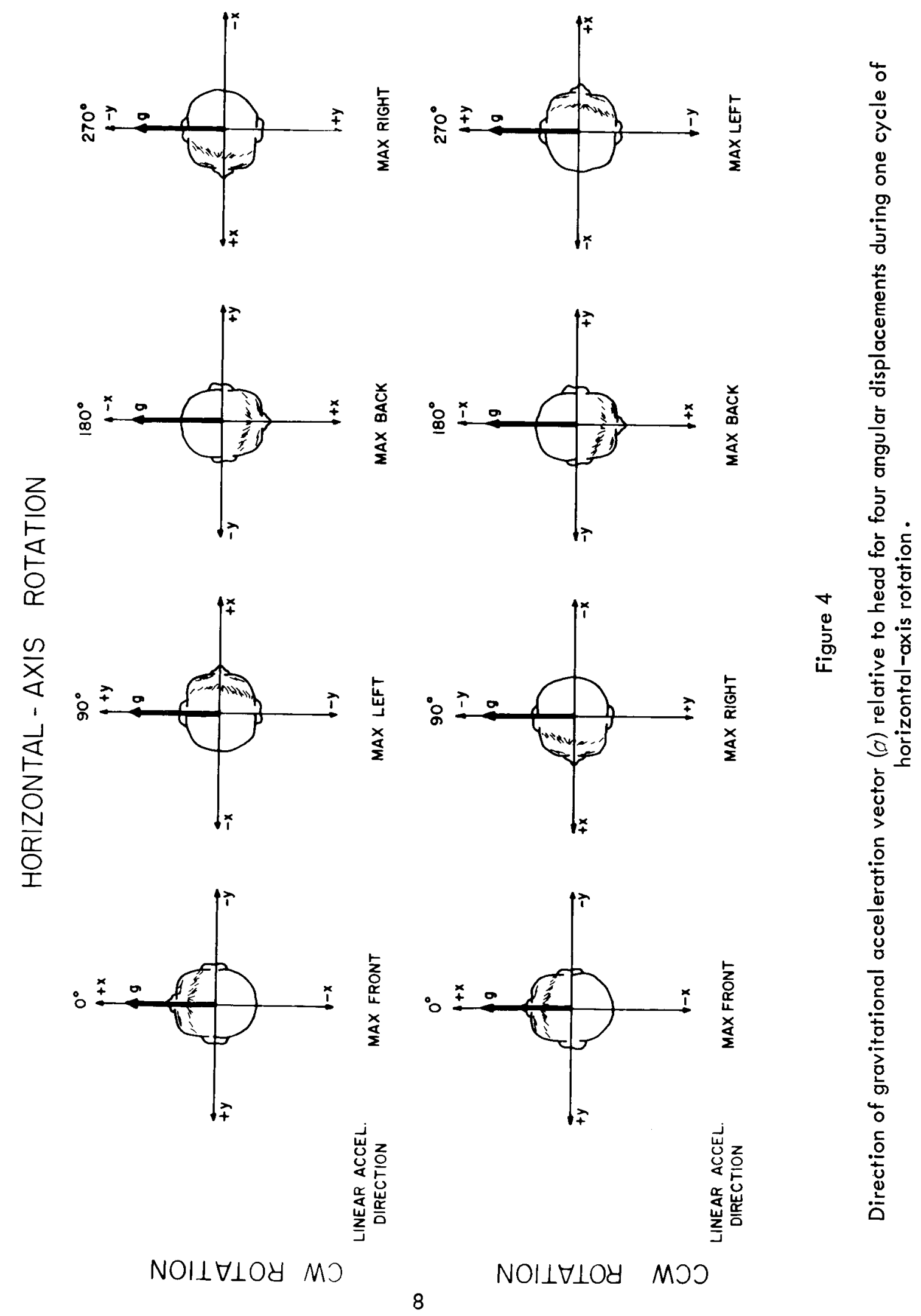



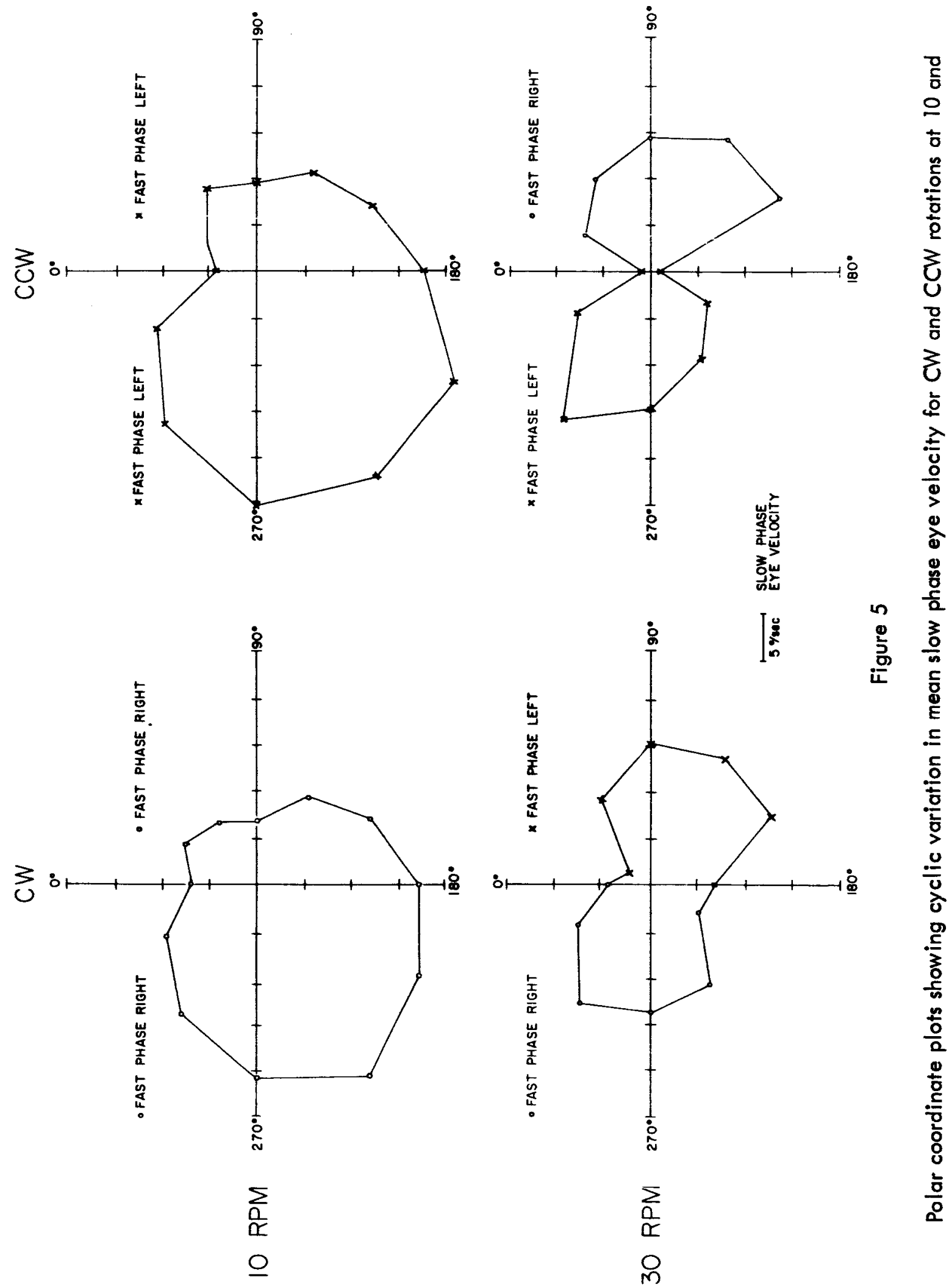

n

온

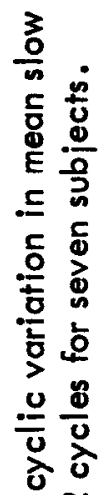

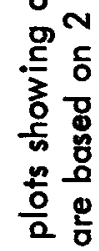

产 喜

훙 우

8

능

홍응 
As with nystagmus, the key-press responses and postural sensations were quite different for 10 and 30 RPM. For 10 RPM the postural sensations were usually approximately veridical as indicated by the subject's verbal description and his key-press responses. Subjects perceived continuous rotation about a horizontal axis and accurately estimated nose-up and nose-down positions. There were two exceptions to the accurate perception of rotation, and these were given by the two subjects who produced reversing nystagmus during $10 \mathrm{RPM}$. Both reported disorientation and were unable to signal positions by key pressing during rotation in the direction which produced reversing nystagmus. The same subjects gave accurate signals of spatial positions and descriptions of body motion during rotation directions which produced unidirectional nystagmus. After thirty to forty seconds at 30 RPM, all subjects, except one*, exhibited responses similar to those of subjects with labyrinthine dysfunction (3) in that they were unable to estimate body positions accurately, and their descriptions of body motions ranged from vertical-axis rotation to horizontal-axis rotation with the nose always pointing down or always pointing up. This disorientation usually began after about thirty seconds of rotation at 30 RPM and was indicated by the inability of most subjects to key press accurately during the remainder of the rotation interval. Those who key pressed, though inaccurately, said that they were disoriented but attended to pressure cues for their estimates of nose-up and nose-down. During 30 RPM the onset of disorientation was closely associated with beginning of the reversing nystagmus. As shown in Figure 6, subjects signaled body position accurately while the nystagmus remained unidirectional; however, when the nystagmus started reversing (lower panel) the subject no longer could estimate the nose-up position. Many subjects either stopped key pressing altogether or gave signals which showed little relationship to true body position.

\section{SICKNESS}

A high incidence of sickness was observed in this experiment. Twelve of the twenty subjects were unable to complete the experimental sequence. A relationship between mental task required of the subject and incidence of sickness was noted. Of the twelve subjects who could not complete the sequence, all had been asked to attend to postural sensations with the purpose of giving accurate verbal and pictorial descriptions of the motion profile experienced during the runs. Of the eight who completed, four were given the key-press task and four were required to perform mental arithmetic during the rotation trials. This relationship between sickness and mental task confirms similar earlier observations (2).

- - - - . - . - -

* This single exception had unidirectional nystagmus and maintained essentially veridical spatial orientation throughout 30 RPM rotation. 


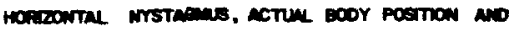

staEctre ESTMATE OF MOSE UP NO NOEE Dow

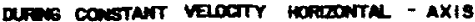

ROTATION AT 30 RPM
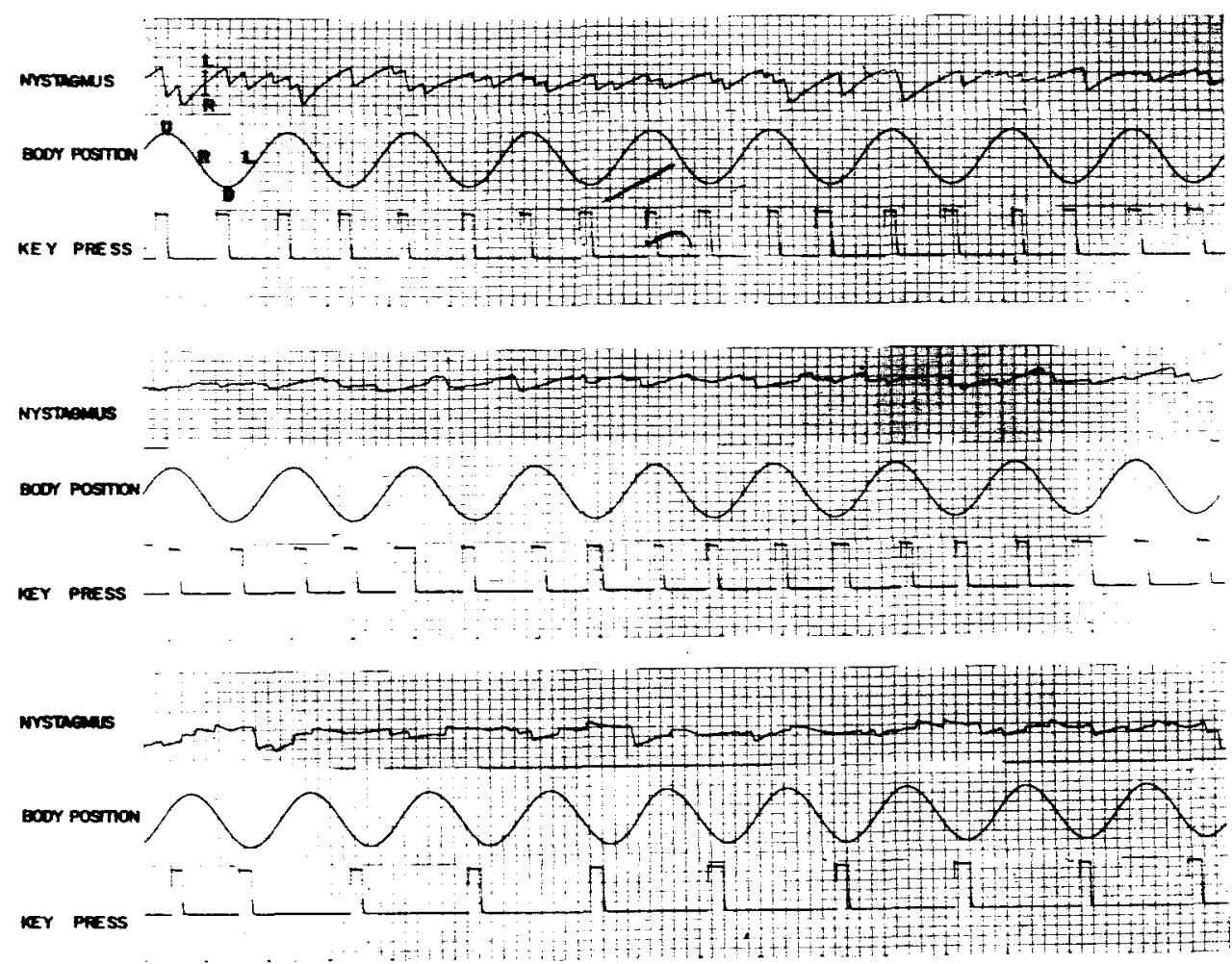

Figure 6

Recordings showing coincidence on onset of reversing horizontal nystagmus and deterioration of position signals. Note that, a long nystagmus is unidirectional, subject is able to estimate nose-up and nose-down positions.

\section{DISCUSSION}

The time course of the nystagmus for the 10 RPM trials of the present experiment demonstrated the same general trend as that noted in previous experiments involving horizontal-axis rotation $(1,3)$, namely, a sustained unidirectional horizontal nystagmus which persisted well beyond that observed for comparable verticalaxis rotation. Nystagmus at 30 RPM was continuous during this interval when angular acceleration would be effective; however, a reversing nystagmus was observed after this period. Generally, subjects who produced a unidirectional response at 10 RPM produced a clear reversing nystagmus at 30 RPM for comparable time intervals of constant velocity rotation. At 30 RPM when the reversing nystagmus commenced, the direction and magnitude of the nystagmus appeared to be related to the magnitude and direction of the grovitational linear acceleration vector along the subject's leftright $(y)$ head axis. This relationship between nystagmus and linear acceleration 
relative to the skull has previously been pointed out for several stimulus configurations including linear oscillation on a horizontal track (6). Similarly, at 10 RPM, the orientation of the gravity vector relative to the horizontal head axes appeared to modulate the magnitude of the unidirectional nystagmus during the period of constant velocity as shown in Figure 5 . Analysis of nystagmus during angular acceleration (footnote, p. 5) and deceleration (2) demonstrates that reorientation relative to gravity influences nystagmus during these phases of horizontal-axis rotation. The peak nystagmic response was greater during acceleration and less during deceleration with the rotational axis horizontal as compared to rotation with the axis vertical. These response differences are reasonable since during angular acceleration and reorientation relative to gravity, there is a coordinated input from both sets of stimuli; during and after deceleration, sensory input is discordant. Upon being stopped (not reoriented relative to gravity) otoliths and pressure senses signal the stopped condition while the canals signal counterrotation in response to angular deceleration.

To explain the continuous unidirectional nystagmus observed during horizontalaxis rotation at lower velocities, Benson and Bodin (1) suggested that endolymph flow could develop due to differences in specific gravity of the perilymph and the endolymphfilled membranous labyrinth. It was further suggested that this mode of response would not persist at higher angular velocities where the dynamic properties of the membranous labyrinth, endolymph, and perilymph would limit continued responding by this mode. In the present experiment, however, a reversing nystagmus was observed as the rate of rotation was increased to a higher velocity. This finding does not negate the BensonBodin hypothesis, but it does raise questions as to the latter being the only deviation from the commonly accepted mode of response during horizontal-axis rotation.

The finding of two types of nystagmus as a function of rate of horizontal-axis rotation forces consideration of several modes of response for the canals and the otolith organs. It is likely that both the semicircular canals and otolith organs act in concert during horizontal-axis rotation, each with different response ranges and each shifting response modes, but at different frequencies of sustained reorientation relative to gravity. 


\section{REFERENCES}

1. Benson, A. J., and Bodin, M. A., Interaction of linear and angular accelerations on vestibular receptors in man. Aerospace Med., 37: 144-158, 1966.

2. Correia, M. J., and Guedry, F. E., Influence of labyrinth orientation relative to gravity on responses elicited by stimulation of the horizontal semicircular canals. NSAM-905. NASA Order No. R-93. Pensacola, Fla.: Naval School of Aviation Medicine, 1964.

3. Guedry, F. E., Orientation of the rotation-axis relative to gravity: Its influence on nystagmus and the sensation of rotation. Acta otolaryng., Stockh., 60: 30-48, 1965.

4. Guedry, F. E., and Harris, C. H., Labyrinthine function related to experiments on the parallel swing. NSAM-874. NASA Order No. R-93. Pensacola, Fla.: Naval School of Aviation Medicine, 1963.

5. Hixson, W. C., and Niven, J. I., A bioinstrumentation control center for the Human Disorientation Device. NSAM-848. NASA Order No. R-1. Pensacola, Fla.: Naval School of Aviation Medicine, 1963.

6. Niven, J. I., Hixson, W. C., and Correia, M. J., Elicitation of horizontal nystagmus by periodic linear acceleration. NAMI-953. NASA Order No. R-93. Pensacola, Fla.: Noval Aerospace Medical Institute, 1965. 


\section{DOCUMENT CONTROL DATA - R\&D}

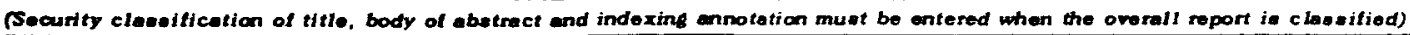

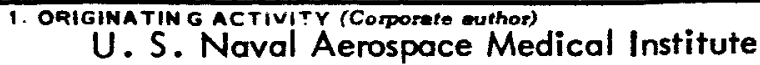

Pensacola, Florida
2. REPORT SECURITY CLASSIFICATION Unclassified

2 b. GROUP

N/A

3. AEPORT TITLE

MODIFICATION OF VESTIBULAR RESPONSES AS A FUNCTION OF RATE OF

ROTATION ABOUT AN EARTH HORIZONTAL AXIS

4. DESCRIPTIVE NOTES (TYPe oi ropori aft treflunive datoes)

N/A

5. AUTHOR(S) (Laet name, first neme, inttial)

Correia, Manning J., and Guedry, Fred E., Jr.

\begin{tabular}{|c|c|c|}
\hline $\begin{array}{l}\text { 6. REPO RT DATE } \\
24 \text { March } 1966\end{array}$ & $\begin{array}{l}\text { 7a. TOTAL NO. OF PAGES } \\
13\end{array}$ & $\begin{array}{l}\text { 7b. NO. OF REFS } \\
6\end{array}$ \\
\hline $\begin{array}{l}\text { 6. contract on grant no. NASA Order R-93 } \\
\text { b. PROJect no. MR005.13-6001.1 }\end{array}$ & \multicolumn{2}{|c|}{ 9A. ORIGINATOR'S REPOAT NUMBER(S) } \\
\hline c. & $\begin{array}{l}\text { 9b. OTHER REPORT NO(S) } \\
\text { HIA ROPOF) } \\
129\end{array}$ & other numbere thet may be aesiened \\
\hline
\end{tabular}

10. AVAILAEILITY/LIMITATION NOTICES

Qualified requesters moy obtain copies of this report from DDC. Available, for sale to the public, from the Clearinghouse for Federal Scientific and Technical Information, Springfield, Virginia, 22151.

\begin{tabular}{|l|l}
\hline 11. SUPPL EMEN TARY NOTES & 12. SPONSORING MILITARY ACTIVITY
\end{tabular}

13. ABSTRACT

Eight men were rotated about an Earth horizontal axis at velocities of 10 and 30 RPM. Both nystagmus and subjective estimates of body position in space were modified by the high rate of rotation. Subjects who gave essentially veridical estimates of body position at 10 RPM became disoriented at 30 RPM and gave responses closely resembling those of subjects with labyrinthine dysfunction. Subjects who produced sustained unidirectional horizontal nystagmus during constant velocity rotation at 10 RPM produced a reversing horizontal nystagmus during comparable intervals of rotation at 30 RPM. Nystagmus slow phase velocity for both 10 and 30 RPM exhibited a cyclic modulation which was related to orientation relative to gravity. As in previous studies, sickness was produced by rotation about a horizontal axis, and a relationship between mental task and incidence of sickness was again noted. 
UNCLASSIFIED

Security Classification

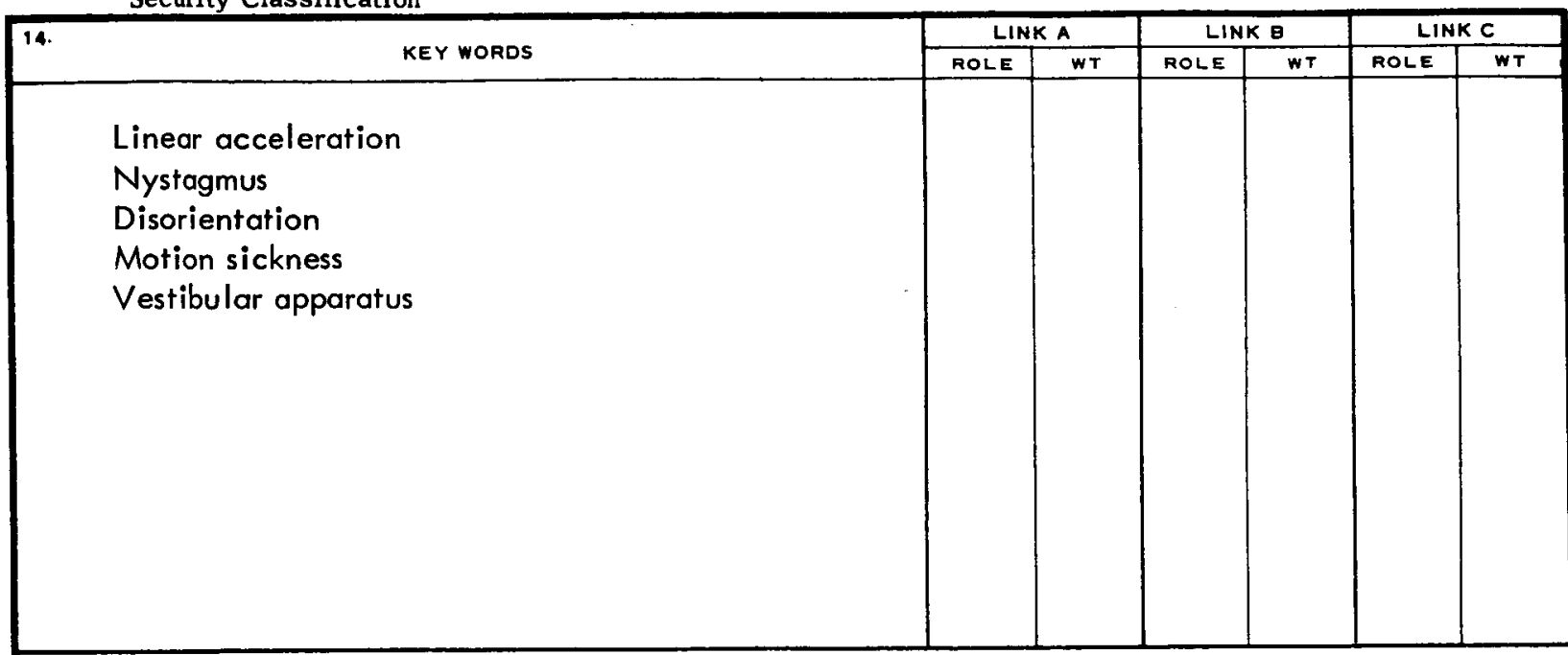

\section{INSTRUCTIONS}

1. ORIGINATING ACTIVITY: Enter the name and address of the contractor, subcontractor, grantee, Department of Defense activity or other organization (corporate author) issuing the report.

2a. REPORT SECURTY CLASSIFICATION: Enter the overall security classification of the report. Indicate whether "Restricted Data" is included Marking is to be in accordance with appropriate security regulations.

2b. GROUP: Automatic downgrading is specified in DoD Directive 5200.10 and Armed Forces Industrial Manual. Enter the group number. Also, when applicable, show that optional markings have been used for Group 3 and Group 4 as authorized.

3. REPORT TITLE: Enter the complete report title in all capital letters. Titles in all cases should be unclassified. If a meaningful title cannot be selected without classification, show title classification in all capitals in parenthesis immediately following the title.

4. DESCRIPTIVE NOTES: If appropriate, enter the type of report, e.g., interim, progress, summary, annual, or final. Give the inclusive dates when a specific reporting period is covered.

5. AUTHOR(S): Enter the name(s) of author(s) as shown on or in the report. Enter last name, first name, middle initial. If military, show rank and branch of service. The name of the principal author is an ahsolute minimum requirement.

6. REPORT DATE: Enter the date of the report as day, month, year; or month, year. If more than one date appears on the report, use date of publication.

7a. TOTAL NUMBER OF PAGES: The total page count should follow nomal pagination procedures, i.e., enter the number of pages containing information.

7b. NUMBER OF REFERENCES: Enter the total number of references cited in the report.

8a. CONTRACT OR GRANT NUMBER: If appropriate, enter the applicable number of the contract or grant under which the report was written.

8b, 8c, \& 8d. PROJECT NUMBER: Enter the appropriate military department identification, such as project number, subproject number, system numbers, task number, etc.

9a. ORIGINATOR'S REPORT NUMBER(S): Enter the official report number by which the document will be identified and controlled by the originating activity. This number must be unique to this report.

9b. OTHER REPORT NUMBER(S): If the report has been assigned any other report numbers (either by the originator or by the sponsor), al so enter this number(s).

10. AVAIL ABILITY/LIMITATION NOTICES: Enter any limitations on further dissemination of the report, other than those imposed by security classification, using standard statements such as:

(1) "Qualified requesters may obtain copies of this report from DDC."

(2) "Foreign announcement and dissemination of this report by DDC is not authorized."

(3) "U. S. Government agencies may obtain copies of this report directly from DDC. Other qualified DDC users shall request through

(4) "U. S. military agencies may obtain copies of this report directly from DDC Other qualified users shall request through

(5) "All distribution of this report is controlled Qual. ified DDC users shall request through ."

If the report has been furnished to the Office of Technical Services, Department of Commerce, for sale to the public, indicate this fact and enter the price, if known

11. SUPPLEMENTARY NOTES: Use for additional explanatory notes.

12. SPONSORING MILITARY ACTIVITY; Enter the name of the departmental project office or laboratory sponsoring (pay ing for) the research and development. Include address.

13. ABSTRACT: Enter an abstract giving a brief and factual summary of the document indicative of the report, even though it may also appear elsewhere in the body of the technical report. If additional space is required, a continuation sheet shall be attached.

It is highly desirable that the abstract of classified reports be unclassified. Each paragraph of the abstract shall end with an indication of the military security classification of the information in the paragraph, represented as (TS), (S), (C), or (U)

There is no limitation on the length of the abstract. However, the suggested length is from 150 to 225 words.

14. KEY WORDS: Key words are technically meaningful terms or short phrases that characterize a report and may be used as index entries for cataloging the report. Key words must be selected so that no security classification is required. Identifiers, such as equipment model designation, trade name, military project code name, geographic location, may be used as key words but will be followed by an indication of technical context. The assignment of links, rales, and weights is optional. 